\title{
Disability and health status: ethnic differences among women in the United States
}

\author{
Elena M Andresen, Ross C Brownson
}

\begin{abstract}
Study objectives-There are few data describing disability and health status for ethnic groups. The disablement process involves social influences, which may include minority status. Cross sectional data were examined to investigate the relation of ethnicity to disability.

Design-A stratified random digit dialled sample of women aged 40 and older. Disability and health status were measured as functional and activity limitations, work disability, and days of poor physical and mental health.

Setting-United States.

Participants-Women interviewed by telephone included 774 white, 749 AfricanAmerican, 660 Hispanic, and 739 Native American women.

Main results-The prevalence of disability was higher among minority women when classified by general health status, and the need for personal care assistance. There was a striking excess of work disability: $3.5 \%$ of white women compared with $7.1 \%$ to $10.3 \%$ for minority women. The differences were reduced when adjusted for other risk factors and socioeconomic status. White and minority women reported more similar disability when it was defined by poor mental and physical health days.

Conclusions-Disability is correlated with social and demographic characteristics as well as medical diagnoses. Ethnicity also is associated with disability and may be part of a social context for disablement. Future research should concentrate on the temporal sequence of disability. Consistent definitions of disability will facilitate this research.

(F Epidemiol Community Health 2000;54:200-206)
\end{abstract}

Public health researchers continue to broaden the types of health events they study and now include not only the aetiology of specific diseases and mortality, but also the outcomes of disease. Outcomes include heterogeneous conditions classified by general health, function, and disability status. Both surveillance activities and analytic research examine these health differences among groups to report and understand disparities. In the United States, public health scientists and practitioners recognise decrements in health and health risk factors based on race and ethnicity and these were targeted in Healthy People 2000, an agenda for public health goals. For example, Healthy People 2000 included a goal of reducing the prevalence of overweight among minority women. ${ }^{1}$ However, there are few national level data gathered specifically to explore these differences, and even when data are available, they have usually been examined for specific disease differences and not for ethnic differences in generic health indicators. In fact, the acquisition of data on the health of minority groups is itself a public health goal in the proposed public health agenda, Healthy People $2010 .^{2}$ The proposal also has a considerably enlarged agenda for disability and health compared with the preceding American public health targets. An even more specific question of interest is whether ethnic groups differ by functional levels, health status, and/or disability.

The theoretical model describing disability and the disablement process recently has been revised by the World Health Organisation. ${ }^{3}$ This model describes and classifies people by impairment (biological level, for example, a spinal cord injury, arthritis) and function (body level, for example, walking), but also includes important aspects of the context, especially the environmental context, with which the person interacts. The context in conjunction with impairment can produce differences in participation at the societal level. Thus, disability is the preventable health state of interest in this model rather than prevention of the primary impairment. Membership in minority groups may be one contextual level characteristic that leads to differences in disability. For example, arthritis is a common condition among American women of different ethnic groups, but differences in culture and social environment and/or barriers may result in different functional levels, or differences in work participation, between ethnic groups. This study reports on ethnic differences in health status and disability from a national sample of white and minority American women aged 40 and older.

\section{Methods}

SAMPLE SURVEYED

Cross sectional data were collected from women during telephone interviews using a cluster sampling technique devised to maximise the likelihood of sampling minority women aged 40 and older throughout the United States. ${ }^{4}$ The random digit dialled sampling strategy was designed to achieve a sample size of approximately 3000 women of selected racial and ethnic characteristics. The methods concentrated on national postal "zip" codes with at least $20 \%$ each of three groups: African American; American Indian/Alaskan Native; and Latina/Hispanic. In addition to minority 
groups, a comparison sample of white women also were surveyed based on methods of the Centers for Disease Control and Prevention (CDC) Behavioral Risk Factor Surveillance System (BRFSS) random digit dialling techniques.

The BRFSS is an ongoing telephone survey of the health and health behaviours of Americans that is conducted by state health departments under the supervision and with the financial support of the CDC. ${ }^{5}$ The methods of this study are described in more detail elsewhere. ${ }^{4-6}$ Briefly, interviews were conducted throughout 12 months (July 1996 to June 1997) to avoid seasonal effects. Four attempts were made to screen each selected telephone number. When a household was reached where an eligible woman resided, an additional three attempts were made to interview her. Response was calculated based on methods described by Remington and colleagues for the BRFSS ${ }^{5}$ that include accounting for working telephone numbers where no contact was made and resulted in $91 \%$ completion. A total of 2922 women was successfully interviewed from the four targeted groups and constitute the sample available for the present analysis. These included 774 white women, 749 African American women, 739 Native women, and 660 Hispanic women. All interviews were conducted in English.

\section{QUESTIONNAIRE}

The telephone survey included 92 questions derived, in part, from the BRFSS, and the National Health Interview Survey. Because the primary focus of this study was on exercise and physical activity, a number of questions were designed specifically for this survey on these topics: These new questions were derived in part from input of focus groups with minority women. ${ }^{6}$ Major topic areas of the survey included demographics; physical activity behaviour, attitudes, barriers and social support; sources of health information; tobacco use and exposure; dietary and weight control practices; and preventive health practices, medical diagnoses, health status and functional status. Women were asked if they had been "told by a doctor" that they selected common chronic diseases and risk factors (for example, high blood pressure, arthritis). Body mass index (BMI) was computed by the formula height/ weight ${ }^{2}$ and women were classified as overweight if their BMI exceeded 27.3.

The CDC developed their own working model of functional health status and health related quality of life (HRQoL) that includes individual, personal network, and societal/ community domains. ${ }^{78}$ Initial CDC surveillance efforts were designed to give objective, individual level information on communityresident adults. ${ }^{7910}$ There is a four question module used by all states and an optional 10 question module used by some states as part of their BRFSS. ${ }^{80-13}$ The BRFSS HRQoL core is well established with standardised survey and scoring methods and has established general population norms, ${ }^{9-12}$ and all 14 questions have been used in disability surveillance and research. ${ }^{13-16}$ (See appendix).

For this study of ethnicity and health, seven questions measured health status, function, and disability. Three of the four question core BRFSS health status/HRQoL items were asked, including general health status (excellent, very good, good, fair, poor), and two questions that ask about poor health days in the past 30 days, one specifically about physical health and one asking about mental health. These two "poor health days" also combine for a summary measure of "good health days" by subtracting each from 30 (negative days are not allowed). These BRFSS core questions were augmented with two disability questions from the BRFSS 10 question optional HRQoL module: "Are you limited in any way in any activities because of any impairment or health problem?" followed by a question asking if the respondent needed personal care assistance because of an impairment or health problem. The latter yields a proxy summary measure of activities of daily living (ADL) function: For the purposes of this study this was combined with the question on limitations and women who reported they were not limited also were assumed not to require personal care assistance. Finally, a question that asked about work status included a category of "disabled and unable to work" that defined women with severe work disability (SWD): Analyses applying this definition of disability were restricted to women aged 40 to $64(n=2207)$. This variable has been found to produce estimates of the prevalence of SWD similar to those generated by the 1990 Census (E A Borawski, et al. Annual Meeting of the American Public Health Association, Indianapolis, 1997). Persons aged 18 to 64 years of age were categorised as having a SWD if they: (1) indicated they were unable to work on the BRFSS occupational status question; (2) indicated they were unemployed, a student, homemaker, or retired AND their self rated health was "poor;" (3) indicated they were unemployed, a student, homemaker, or retired AND reported 14 or greater recent activity limitation days because of poor health.

ANALYSES

Analyses compared each group of minority women to white women (the referent category). Estimates of the prevalence of health status, disability, and other comparisons among groups were performed using weighted data by SPSS $7.5 .{ }^{17}$ As the sampling method was by clusters, but not correlated (only one woman was selected per household), this technique may produce slightly conservative estimates compared with bootstrap, jack-knife, or other techniques for complex sampling methods. Mantel-Haenszel $\chi^{2}$ statistics were used to detect significant differences between white and minority women for simple frequencies and a $\chi^{2}$ for trend was computed to test between group differences for linear trend for variables with ranked categories (for example, education level). Differences between groups for continuous variables were tested with 
Table 1 Descriptive characteristics of minority and white women aged 40 and older

\begin{tabular}{|c|c|c|c|c|c|}
\hline Variable & $\begin{array}{l}\text { Overall } \\
(n=2922)\end{array}$ & $\begin{array}{l}\text { White } \\
(n=774)\end{array}$ & $\begin{array}{l}\text { Black } \\
(n=749)\end{array}$ & $\begin{array}{l}\text { Native } \\
(n=739)\end{array}$ & $\begin{array}{l}\text { Hispanic } \\
(n=660)\end{array}$ \\
\hline Mean (SD) age & $56.1(11.8)$ & $57.3(12.4)$ & $58.9(12.8)$ & $54.4 \ddagger(10.6)$ & $52.8 \ddagger(10.0)$ \\
\hline Married & 58.8 & 63.3 & $32.4 \ddagger$ & 61.8 & 65.4 \\
\hline \multicolumn{6}{|l|}{ Formal education $\dagger$} \\
\hline$<$ high school & 22.2 & 11.1 & 31.4 & 33.5 & 26.9 \\
\hline high school & 30.4 & 30.6 & 29.7 & 30.6 & 30.2 \\
\hline$>$ high school & 47.4 & 58.3 & 38.9 & 35.9 & 42.9 \\
\hline Annual income under $\$ 25000$ & 43.1 & $39.8 \ddagger$ & $71.0 \ddagger$ & $61.5 \ddagger$ & $52.4 \ddagger$ \\
\hline Mean (BMI) (SD) & $27.3(5.9)$ & $25.8(5.1)$ & $29.0 \ddagger(6.9)$ & $29.0 \ddagger(6.1)$ & $27.2 \ddagger(5.4)$ \\
\hline Overweight $(\mathrm{BMI} \geqslant 27.3)$ & 42.9 & 31.3 & $55.8 \ddagger$ & $57.8 \ddagger$ & $40.2 \ddagger$ \\
\hline Currently smoke & 20.6 & 20.4 & 25.1 & 21.0 & $16.3^{\circ}$ \\
\hline Exercise past 2 weeks & 63.4 & 69.3 & 63.1 & $51.3 \ddagger$ & 65.7 \\
\hline Any health insurance & 84.2 & 86.2 & 87.8 & 82.3 & $78.4 \ddagger$ \\
\hline Medicaid (of those reporting any coverage) & 9.1 & 5.8 & $13.9 \ddagger$ & $13.1 \ddagger$ & 7.8 \\
\hline Arthritis* & 42.9 & 41.0 & $51.9 \ddagger$ & 47.4 & $31.6 \neq$ \\
\hline Diabetes* & 14.6 & 10.7 & $23.7 \ddagger$ & $16.2 \ddagger$ & 15.1 \\
\hline Hypertension* & 31.6 & 28.0 & $47.1 \ddagger$ & 33.2 & 24.8 \\
\hline Cholesterol $^{\star}$ & 26.6 & 29.6 & 23.4 & 26.3 & $20.8 \ddagger$ \\
\hline Heart disease ${ }^{\star}$ & 12.0 & 11.5 & 15.4 & 12.7 & 8.5 \\
\hline Cancer ${ }^{\star}$ & 6.9 & 8.8 & 4.6 & 5.5 & 6.1 \\
\hline Depression $\star$ & 18.2 & 16.8 & 17.6 & 20.6 & 18.8 \\
\hline
\end{tabular}

$\star$ Told by a doctor she had this medical condition. $\dagger \chi^{2}$ for trend $\mathrm{p}<0.001$ comparing each group of minority women with white women. $\neq \chi^{2}$ or $t$ test $\mathrm{p} \leqslant 0.01$ compared with white women. Data shown as percentages apart from mean age and mean BMI.

Student's $t$ test. Descriptive statistical results are reported conservatively at $\mathrm{p}<0.01$. Logistic regression analyses were used to compute prevalence odds ratios (POR) and 95\% confidence intervals ( $95 \%$ CI) comparing each group of minority women to white women for the dichotomous measures of health status and disability (work disability, limited by health/ impairment, need personal care, fair or poor health status). Linear regression was used for continuous measures of health status (poor mental and physical health days, good health days). Multivariate regression models were built in a progressive fashion with the intent of estimating the unconfounded effect of race on each outcome variable (a main effect model) rather than producing models with maximum prediction of the disability outcome variables. Potentially confounding variables were identified as those that (1) demonstrated a meaningful difference (ignoring $\mathrm{p}$ value) between the groups of women, and (2) were judged to have a potentially independent effect on disability, but (3) not to be part of the causal pathway. Because of the cross sectional nature of the survey and because causal pathways were difficult to assess, we used a conservative approach in defining confounders and included virtually all covariates when they had an effect on even one of the coefficients for ethnic groups. For example, logistic and linear models were adjusted for variables such as "exercise" unless clearly inappropriate (that is, exercise was not included in the logistic regression model predicting personal care assistance, and depression diagnosis was not included in the linear model predicting poor mental health days). The indicator variable for ethnic group was entered first to logistic and linear regression analyses models and then each potentially confounding variable was tested separately to see if it had a meaningful effect on the size of the POR or regression coefficient (for example, a change of \pm 0.10 in the POR). ${ }^{18}$ These candidate variables were then tested by adding them one at a time in increasingly complex models.

\section{Results}

Table 1 shows the descriptive characteristics of the overall sample and each ethnic group. Except for African American women, a majority of the sample reported they were married. There was a statistically significant trend for white women to have completed a higher level of formal education than minority women and also for their annual income to be higher (nine levels of income, $\chi^{2}$ for trend $p<0.001$ for each group of minority women compared with white women). Slightly higher percentages of white and African American women reported they had some form of health insurance and, among women with coverage, African American and Native American women were more likely to

Table 2 BRFSS and Activity Limitations Questions comparing minority and white women aged 40 and older

\begin{tabular}{|c|c|c|c|c|c|}
\hline BRFSS item & $\begin{array}{l}\text { Overall } \\
(n=2922)\end{array}$ & $\begin{array}{l}\text { White } \\
(n=774)\end{array}$ & Black $(n=749)$ & $\begin{array}{l}\text { Native } \\
(n=739)\end{array}$ & $\begin{array}{l}\text { Hispanic } \\
(n=660)\end{array}$ \\
\hline Mean (SD) days last 30 poor physical health & $4.7(8.7)$ & $4.1(8.1)$ & $5.5(9.3)$ & $5.5(9.5)$ & $4.4(8.3)$ \\
\hline Mean (SD) days last 30 poor mental health & $2.7(6.9)$ & $2.8(6.9)$ & $1.8(5.4)$ & $3.0(7.5)$ & $2.8(7.0)$ \\
\hline Mean (SD) good health days last 30 & $23.4(10.0)$ & $23.8(9.6)$ & $23.4(10.0)$ & $22.8(10.6)$ & $23.5(10.0)$ \\
\hline \multicolumn{6}{|l|}{ General health $\ddagger$} \\
\hline$\%$ excellent & 14.6 & 19.7 & 9.1 & 9.6 & 13.5 \\
\hline$\%$ very good & 24.5 & 29.8 & 17.4 & 19.5 & 24.1 \\
\hline$\%$ good & 33.0 & 30.4 & 35.7 & 36.5 & 32.2 \\
\hline$\%$ fair & 19.2 & 14.6 & 27.0 & 22.5 & 20.0 \\
\hline$\%$ poor & 8.6 & 5.6 & 10.8 & 11.8 & 10.2 \\
\hline$\%$ limited & 24.7 & 23.5 & 27.9 & 28.1 & 19.1 \\
\hline$\%$ personal care & 3.4 & 1.7 & $5.4 \$$ & $5.5 \$$ & 3.3 \\
\hline$\%$ work disabled $\dagger$ & 6.3 & 3.5 & 7.1 & $10.3 \S$ & 7.3 \\
\hline
\end{tabular}

†Of women aged 40-64. $\ddagger \chi^{2}$ for trend $\mathrm{p}<0.001$ comparing each group of minority women with white women. $\delta \chi^{2}$ or $t$ test $\mathrm{p} \leqslant 0.01$ compared with white women. 
Table 3 Logistic regression models comparing white and minority women for risk of reduced health status and disability

\begin{tabular}{|c|c|c|c|c|}
\hline \multirow[b]{2}{*}{ Variables in model } & \multicolumn{4}{|c|}{$\begin{array}{l}\text { Adjusted prevalence odds ratios * (and 95\% confidence intervals) for health status and disability } \\
\text { outcomes }\end{array}$} \\
\hline & Any limitations & Severe work disability & $\begin{array}{l}\text { Fair or poor health } \\
\text { status }\end{array}$ & Personal care \\
\hline Number in model & 2363 & 2117 & 2359 & 2354 \\
\hline White women (reference) & 1.0 & 1.0 & 1.0 & 1.0 \\
\hline African American & $0.62(0.46,0.85)$ & $1.10(0.61,2.00)$ & $1.31(0.96,1.78)$ & $1.93(0.92,4.05)$ \\
\hline Native American & $0.77(0.57,1.04)$ & $1.39(0.80,2.41)$ & $1.31(0.97,1.77$ & $2.05(0.96,4.26)$ \\
\hline Hispanic & $0.72(0.53,0.98)$ & $1.57(0.89,2.76)$ & $1.63(1.20,2.22)$ & $2.06(0.94,4.49)$ \\
\hline Age (per year) & $0.99(0.99,1.01)$ & $1.02(0.99,1.05)$ & $0.98(0.97,0.99)$ & $1.01(0.99,1.03)$ \\
\hline Education $(<\mathrm{HS}, \mathrm{HS},>\mathrm{HS})$ & - & $0.50(0.40,0.62)$ & - & - \\
\hline Marital (no, yes) & $0.92(0.74,1.16)$ & $0.59(0.42,0.84)$ & - & - \\
\hline Insured (no, yes) & $0.67(0.50,0.90)$ & - & - & - \\
\hline Incomet & $0.83(0.74,0.93)$ & $0.87(0.82,0.92)$ & - & $0.84(0.79,0.88)$ \\
\hline Exercise (no, yes) & $0.57(0.46,0.70)$ & - & - & - \\
\hline Arthritis (no, yes) & $4.13(3.31,5.14)$ & $3.03(2.08,4.35)$ & $2.29(1.86,2.83)$ & $2.32(1.39,3.88)$ \\
\hline Diabetes (no, yes) & $1.47(1.12,1.91)$ & $2.08(1.35,3.33)$ & - & $2.20(1.62,3.54)$ \\
\hline Hypertension (no, yes) & $1.43(1.15,1.80)$ & - & $1.88(1.51,2.33)$ & - \\
\hline Heart disease (no, yes) & - & $2.13(1.35,3.33)$ & $3.84(2.83,5.23)$ & $2.66(1.62,4.35)$ \\
\hline Depression (no, yes) & - & $2.70(1.85,2.85)$ & - & $2.26(1.42,3.61)$ \\
\hline Overweight (no, yes) & $1.41(1.13,1.75)$ & $1.20(0.83,1.75)$ & - & $1.06(0.66,1.71)$ \\
\hline BMI (per unit increase) & - & - & $1.04(1.02,1.06)$ & - \\
\hline
\end{tabular}

$\star$ Prevalence odds ratio adjusted for all other variables in the model. $\dagger$ POR per household income category. Referent $<\$ 5000$ per year; $\$ 5000$ to $<\$ 10000 ; \$ 10000$ to $<\$ 15000 ; \$ 15000$ to $<\$ 20000 ; \$ 20000$ to $<\$ 25000 ; \$ 25000$ to $<\$ 35000 ; \$ 35000$ to $<\$ 50000 ; \$ 50000$ to $\$ 75000$.

list Medicaid (government health coverage for persons in poverty) as the source of their health insurance. Medical conditions reported by women also varied by race and ethnicity, and in expected patterns. For example, obesity and diabetes were more common in minority women; the latter was especially more common among African American and Native American women. Hypertension was reported by almost half of African American women compared with one third or less of the other women.

Table 2 lists the descriptive results for each sub-group of women and for the overall sample. There was a striking excess of work disability among all three groups of minority women $(7.1 \%$ to $10.3 \%)$ compared with white women $(3.5 \%)$. Other measures of health and disability varied with some inconsistencies among the four groups of women. African American and Native women tended to report poorer physical health and more disability than white women, while Hispanic women actually reported somewhat better health on one indicator ("limitations due to mental or physical health"). However, African American and
Native American women were much more likely to report they required some kind of personal care assistance, suggesting that their limitation resulted in a greater level of disability and a more dependent role (the comparison between Hispanic women and white women was not statistically significant).

In general, the results of multi-variable models reduced but did not completely erase the group differences shown in table 2. Health characteristics that would be expected to be associated with health status and disability were consistent with expectations. For example, chronic conditions, like arthritis, heart disease, diabetes, etc, were predictors of poorer physical health and disability. Social and demographics characteristics like marital status, higher education and income, were associated with better health and less disability. Table 3 displays the final logistic regression models for the four dichotomous classifications of health and disability. Minority women were somewhat more likely to have poorer health or disability when defined by fair/poor health status, severe work disability, and needing per-

Table 4 Linear regression models comparing white and minority women for risk of differences in health days

\begin{tabular}{llll}
\hline & \multicolumn{2}{l}{$\beta^{\star}$ (SEM) for differences in health days } \\
\cline { 2 - 4 } Variable & Physical health & Mental health & Good health \\
\hline Number in model & 2299 & 2815 & 2272 \\
$r^{2}$ for this model & 0.143 & 0.041 & 0.177 \\
White women (reference) & - & - & - \\
African American & $-0.888(0.496)$ & $-1.107(0.353)$ & $1.770(0.696)$ \\
Native American & $-0.594(0.475)$ & $-0.010(0.350)$ & $0.917(0.676)$ \\
Hispanic & $-0.437(0.480)$ & $-0.010(0.357)$ & $0.917(0.676)$ \\
Age (per year) & $-0.006 \dagger(0.017)$ & $-0.007 \dagger(.011)$ & $0.148 \dagger(0.023)$ \\
Married (no, yes) & $0.666(0.372)$ & $-0.773 \dagger(0.264)$ & - \\
Education (< high school, high school, > high school) & $-0.467(0.241)$ & - & $0.791 \dagger(0.338)$ \\
Incomeł & $-0.231(0.094)$ & - & $0.210(0.125)$ \\
Depression (no, yes) & $3.669 \dagger(0.440)$ & - & $-9.031 \dagger(0.623)$ \\
Exercise (no, yes) & $-2.484 \dagger(0.348)$ & $-0.947 \dagger(0.260)$ & $3.155 \dagger(0.491)$ \\
Arthritis (no, yes) & $2.379 \dagger(0.367)$ & - & $-2.718 \dagger(0.518)$ \\
Heart disease (no, yes) & $2.519 \dagger(0.551)$ & - & $-2.792 \dagger(0.773)$ \\
Diabetes (no, yes) & $1.259 \dagger(0.478)$ & - & - \\
Cholesterol (no, yes) & $1.484 \dagger(0.388)$ & $1.366 \dagger(0.290)$ & $2.572 \dagger(0.548)$ \\
Smoking (no, yes) & - & $1.364 \dagger(0.317)$ & - \\
BMI (per unit increase) & $0.008+(0.030)$ & - & $-0.008 \dagger(0.063)$ \\
\hline
\end{tabular}

$\star$ Unstandardised $\beta$ coefficient adjusted for all other variables in the model. $t \mathrm{p}$ value $<0.01$. $\ddagger$ Per household income category. Referent $<\$ 5000$ per year; $\$ 5000$ to $<\$ 10000 ; \$ 10000$ to $<\$ 15000 ; \$ 15000$ to $<\$ 20000 ; \$ 20000$ to $<\$ 25000 ; \$ 25000$ to $<\$ 35000$; $\$ 35000$ to $<\$ 50000 ; \$ 50000$ to $\$ 75000$. 
sonal care assistance. These increased risks included the null $(\mathrm{POR}=1.0)$ value except for Hispanic women's risk of fair or poor health $(\mathrm{POR}=1.63,95 \%$ CI $1.20,2.22)$. In contrast, white women were more likely to report disability when it was defined activity limitation. The decreased risk was significant for the comparison with African American women (POR 0.62, 95\% CI 0.46, 0.85) and Hispanic women (POR 0.72, 95\% CI 0.53, 0.98).

Table 4 displays the adjusted estimates for the three "health days" variables. While the unadjusted comparisons (table 2) indicated an uneven pattern of health, the adjusted results were consistent in showing a trend toward fewer days of poor health among minority women, although none of these differences showed a statistically significant difference. For the composite index of good health days, African American women reported an adjusted mean increase of about 1.8 days per month, and Native American and Hispanic women reported an increase of almost one day per month over the mean for white women.

\section{Discussion}

There are a large number of definitions of disability and no universal standard exists for surveillance data. ${ }^{19}$ As an example, the BRFSS question on "limited in any activity" would produce logically higher prevalence estimates of disability compared with the National Health Interview Survey measure, which classifies disability based only on limitations in the major activity. ${ }^{20}$ Lack of consistency makes it difficult to interpret reports and to understand potential disparities among groups. The theoretical construct of the disablement process has been improved and is still ongoing as part of an effort by the World Health Organisation. ${ }^{3}$ Future surveillance and research will benefit from the development of more concise measures of disability and interpretation of the inconsistent results of this study is limited by the currently available surveillance measures.

We found that disability and lower health status were somewhat more common among minority women when defined by self reported general health, work disability, and needing personal care assistance. This disparity was substantially reduced when adjusting for age and other predictors of poor health outcomes. Other measures of general health status gave conflicting results, for example, in unadjusted comparisons, minority women reported somewhat greater poor physical health days, but similar poor mental health days compared with white women: Both measures suggested minority women had a slight advantage after adjusting for other factors associated with reduced health status. However, work disability and needing assistance with personal care, which are the two indicators available in this study with a fairly consistent utility in defining disability, were also consistent in showing a decrement in health for minority women. ${ }^{19}$

Regardless of the definition of health or disability, variables measuring health, demographic, and social factors showed strong relations in this study. Increasing age, medical
KEY POINTS

- Membership in specific ethnic groups may be a contextual level characteristic that is associated with differences in disability.

- There was a striking excess of work disability among minority women $(7.1 \%$ to $10.3 \%$ ) compared with white women (3.5\%).

- There is no universal standard definition of disability for surveillance data, which hampers comparisons among studies.

- More research is needed to understand the nature and causes of disability differences in minority groups.

conditions such as arthritis and diabetes, and characteristics such as being overweight were consistently associated with poorer health and disability. Also predictive of poorer health were social characteristics suggesting disadvantage, for example lower levels of education and income also were associated with lower health status and increased disability. However, even in models that included these characteristics, minority women were still at higher risk of disability (severe work disability and needing personal care), suggesting that traditional socioeconomic factors do not completely explain the discrepancy in health for minority women. The results suggest that minority women do experience some health disparity in terms of disability and health status in part attributable to social, economic, and medical care disadvantage.

Race and ethnicity are interpreted as social constructs rather than biological categories. ${ }^{21-25}$ As such, including covariates that measure social characteristics or health problems that are a result of disadvantage may result in an over-adjustment when investigating decrements in health. Thus, these results should be interpreted as providing conservative estimates of the disadvantage in health and disability for minority women in the United States. Interpretation is limited, however, because the data are cross sectional and the temporal sequence of disability and other covariates cannot be determined. Longitudinal research that disentangles the disablement process is urgently needed to provide a better understanding of existing disparities.

The results of this study are consistent with the sparse reports on health status and disability among American women. Cross sectional results from the Health and Retirement Survey for adults aged 51 to 61 showed an increased prevalence of fair/poor health status and work disability among African American and Hispanic women compared with white women. ${ }^{26}{ }^{27}$ In particular, Bound and colleagues also found that poor health seemed to have a stronger effect on labour force participation among minorities than for white people: This may suggest additional social factors explain the greater work disability of minority women. ${ }^{26}$ Similar to the current report, data from the National Health Interview Survey also report a 
higher prevalence of fair/poor health for African American compared with white women. ${ }^{28}$ Although comparable population means for health days have not been reported, the 1996 BRFSS reported a state median value of 3.3 poor health days and 3.5 poor mental health days for women aged 18 and older. ${ }^{29}$ The increase in poor physical health days ( 4.7 days) and lower poor mental health days (2.7 days) reported here also are consistent with overall levels from previous reports using the BRFSS, where physical health decreased and mental health increased with increasing age. ${ }^{9}$ African Americans in Kansas were found to have lower self reported heath status, ${ }^{30}$ and rural New Mexico American Indians reported lower health based on mental and physical health days but fewer limited activity days based on the BRFSS. ${ }^{31}$ Our findings also confirm other studies about the strong role of arthritis and obesity in producing disability and reduced health status. ${ }^{32-34}$ However, comparative data are sparse and underscore the need for more detailed surveillance information for other special groups. In particular, we were unable to find any published comparative data for Native American women. This study is an important step in describing the health and disability of American women.

Future research is needed to understand the nature of ethnic health differences, but also in the measurement and classification of disability. This study is limited in its ability to suggest there is some disparity for minority women. The fairly broad and heterogeneous classifications of disability and health status are not likely to have produced spurious results of difference among the race and ethnic groups, rather they may have limited the potential for reporting more specific disparities (a bias toward the null). There also is considerable heterogeneity in the broad classifications of ethnic groups. In particular, combining among Hispanic subgroups is an example where social structures and factors that affect health may be especially heterogeneous. ${ }^{35}$ In addition, this study excluded women who could not or were unwilling to be interviewed in English, limiting the generalisability of these results.

Merril and colleagues reported that differences in functional limitations between white and minority women were attributable to actual differences in performance, and not differences in reporting. ${ }^{36}$ This suggests that the effect of disability misclassification is nondifferential among race and ethnic groups and again, may have limited our ability to report true differences. The association of disability with race, ethnicity, and other social contextual factors is consistent with a social model of disablement. ${ }^{3}$ Despite the variety of definitions used here to describe health differences, there is some indication of an overall pattern showing health decrements in minority women, especially for African American and Native American women. However, the pattern is uneven, and the reasons for the lack of uniform results is not clear. The magnitude of these health differences, when they were observed, was explained completely or in part (depending on

the definition of health and disability), by differences in comorbid conditions, social characteristics and socioeconomic status. The role of social context in producing disability requires additional research to assist in developing policies and interventions. However, social disadvantage, potentially including minority status, may be an important contributor.

Disability has gained prominence as a key public health issue. ${ }^{27}$ State level epidemiological surveillance efforts are now underway, with a primary goal of assessing the magnitude of disability assessed by broadly defined disability domains. $^{38} 39$ Variations in health status for subgroups and the measurement issues described in this study may provide insights and priority issues for planning use of limited resources for public health surveillance and evaluation activities.

Our special thanks go to Amy Eyler, Robyn Housemann, and Our special thanks go to Amy Eyler, Robyn Housemann, and
Yuh-Ling Shyu for their assistance with data management and Yuh-Lin
analysis.

Funding: this project was funded through the Centers for DisFunding: this project was funded through the Centers for Disers for Research and Demonstration of Health Promotion and ers for Research and Demonstration of Health Promotion and
Disease Prevention), including support from the Community Disease Prevention), including support from the Comm
Prevention Study of the NIH Women's Health Initiative. Prevention Study of the NIH
Conflicts of interest: none.

\section{Appendix}

Health Status/Health Related Quality of Life (HRQoL) questions from the centers for Disease Control and Prevention (CDC) Behavioral Risk Factor Surveillance System.

Core module questions used *

(1) Would you say that in general your health is: Please Read

a. Excellent

b. Very good

c. Good

d. Fair

e. Poor

Do not read these responses

Don't know/Not sure

Refused

(2) Now thinking about your physical health, which includes physical illness and injury, for how many days during the past 30 days was your physical health not good?

(3) Now thinking about your mental health, which includes stress, depression, and problems with emotions, for how many days during the past 30 days was your mental health not good?

Optional module questions used ${ }^{\star}$

(4) Are you limited in any way in any activities because of any impairment or health problem? (if yes, answer 5) a. Yes

b. No

Don't know/Not sure

Refused

1 2

5) Because of any impairment or health problem, do you need the help of other persons with your personal care needs, such as eating, bathing, dressing, or getting around the house? a. Ye

b. No

Don't know/Not sure

Refused

*There are four questions for the BRFSS HRQoL core module and 10 for the optional module. This study used the five questions shown here, plus "good health days" combining questions 2 and 3 , and severe work disability.

1 Public Health Service. Healthy People 2000: national health promotion and disease prevention objectives - full report, with commentary. Washington, DC: US Department of Heath and Human Services, Public Health Service, 1991; DHHS publication no. (PHS) 91-50212.

2 hublication no. (PHS) 91-50212.

2 http: Ilweb.health.govlhealthypeople
3 ICIDH-2: International classification of impairments, activities, and participation. A manual of dimensions of disablement and
and and participation. A manual of dimensions of disablement and
health. WHO. International classification of functioning and 
disability (ICIDH-2). Beta-2 draft full version. Geneva: WHO, 1999. Beta-1 draft for field trials. Geneva: World Health Oranization, 1997 .

4 Brownson RC, Eyler AA, King AC, et al. Reliability of information of physical activity and other chronic disease risk factors among US women aged 40 and older. Am $\mathcal{F}$ Epidemiol 1999;149:379-9

5 Remington PL, Smith MY, Williamson DF, et al. Design, characteristics, and usefulness of state-based Behaviora Risk Factor Surveillance: 1981-1987. Public Health Rep 1988;103:366-75.

6 Eyler AA, Baker E, Cromer LC, et al. Physical activity and minority women: A qualitative study. Health Educ Behav 1998;25:640-52.

7 CDC. Workshop on quality of life/health status surveillance for states and communities: report of a meeting held on December 2-4, 1991, Stone Mountain Georgia. Atlanta: Centers for Disease Control and Prevention, 1993a.

8 CDC. Consultation of functional status surveillance for states and communities: report of a meeting held on fune 4-5, 1992, Decatur, Georgia. Atlanta: Centers for Disease Control and Decatur, Georgia. A

9 CDC. Quality of life as a new public health measure Behavioral Risk Factor Surveillance System, 1993 MMWR 1994;43:375-80

10 CDC. Health-related quality of life and activity limitationeight states, 1995. MMWR 1998a;47:134-40.

11 Newschaffer CJ. Validation of the BRFSS HRQOL measure in a statewide sample. Atlanta: US Department of Health and Human Services, CDC, 1998.

12 Hennessy CH, Moriarty DG, Zask MM, et al. Measuring health-related quality of life for public health surveillance. Public Health Rep 1994;109:665-72.

13 Andresen EM, Prince-Caldwell, A, Akinci F, et al. The Missouri Disability and Health Project. Am F Prev Med 1999; 16:67-71

14 Andresen EM. Population measurement of health-related quality-of-life (HRQoL). Quality of Life Newsletter 1999;21: 7.

15 Andresen EM, Fouts BS, Romeis JC, et al. Performance of health-related quality-of-life instruments in a spinal cord injured population. Arch Phys Med Rehabil 1999;80 $877-84$

16 Nanda U, Andresen EM. Performance of measures of health-related quality of life and function among disabled adults. [Abstract]. Qual Life Res 1998;7:644.

17 SPSS for Windows V7. 5.2. Chicago: SPSS Inc, 1996.

18 Greenland S. Modeling and variable selection in epidemiologic analysis. Am f Public Health 1989;79:340-9.

19 Adler M. People with disabilities: Who are they? In: Beyond the water's edge: charting the course of managed care for people with disabilities. Washington: Office on Disability, Aging and Long-Term Care Policy/ASPE/DHHS, 1996.

20 LaPlante M, Carlson D. Disability in the United States: prevalence and causes, 1992. Disability Statistics Report (7).
Washington, DC: U S Department of Education, National Institute of Disability and Rehabilitation Research, 1996.

21 Morgenstern H. Defining and explaining race effects. Epidemiology 1997;8:609-11.

22 Hogue CJR. Getting to why. Epidemiology 1997;8:230.

23 Kaufman JS, Cooper RS. In search of the hypothesis. Public Health Rep 1995;110:662-6.

24 Kaufman JS, Cooper RS, McGee DL. Socioeconomic status and health in blacks and whites: The problem of residual confounding and the resiliency of race. Epidemiology 1997; 8:621-8.

25 Fullilove MT. Comment: Abandoning "race" as a variable in public health research- and idea whose time has come. Am F Public Health 1998;88:1297-8.

26 Bound J, Schoenbaum M, Waidmann T. Race differences in labor force attachment and disability status. Gerontologist 1996;36:311-21.

27 Santiago AM, Muschkin CG. Disentangling the effects of disability status and gender on the labor force supply of Anglo, Black, and Latino older workers. Gerontologist 1996; 36:299-310.

28 National Center for Health Statistics. Health, United States, 1995. Hyattsville, MD: Public Health Service, 1996.

29 http: \www.cdc.gov/nccdphp/brfss/index.asp

30 CDC. Factors associated with self-perceived excellent and very good health among blacks - Kansas, 1995. MMWR 1996;45:906-11.

31 Gilliand FD, Mahler R, Davis SM. Health-related quality of life for rural American Indians in New Mexico. Ethnicity Health 1998;3:223-9.

32 Callahan LF, Rao J, Boutaugh M. Arthritis and women's health: prevalence, impact, and prevention. Am f Prev Med 1996;12:401-9.

33 CDC. Factors associated with prevalent self-reported arthritis and other rheumatic conditions-United States, 1989-1991. MMWR 1996;45:487-91.

34 Ensrud KE, Nevitt MC, Cauley JA, et al. Correlates of impaired function in older women. F Am Geriatr Soc 1994; 42:481-9.

35 Marin G, Marin BVO. Research with Hispanic populations. Newbury Park, CA: Sage Publications, 1991.

36 Merrill SS, Seeman TE, Kasl SV, et al. Gender differences in the comparison of self-reported disability and performance measures. F Gerontol 1997;52A:M19-26.

37 Institute of Medicine (IOM). Pope AM, Tarlov AR, eds. Disability in America. Toward a national agenda for prevention. Washington, DC: National Academy Press, 1991.

38 CDC. Program Announcement 730. State disability and health capacity-building. Atlanta: Office on Disability and Health, National Center for Environmental Health, Centers for Disease Control and Prevention, 1997.

39 http://www.cdc.gov/nceh/programs/disabil/states.htm 